\title{
Features of the organization of agroclusters in the structure of land management projects
}

\author{
Abdugani Mukumov ${ }^{1,}$, Komil Xujakeldiev ${ }^{2}$, Fayzullo Xamidov ${ }^{3}$, Sharafatdin Narbaev ${ }^{4}$ and \\ Khudoyberdi Abdivaitov ${ }^{1}$ \\ ${ }^{1}$ Tashkent Institute of Irrigation and Agricultural Mechanization Engineers (TIIAME), Land Use \\ Department, 39 Kari Niyazov Street, Uzbekistan \\ ${ }^{2}$ Karshi Engineering Economic Institute (KMI), Geodesy and Cadastre Department, 225 Mustakillik \\ Avenue, Uzbekistan \\ ${ }^{3}$ Bukhara Branch of the Tashkent Institute of Irrigation and Agricultural Mechanization Engineers \\ (BBTIIAME), 200105, Bukhara city, Gazli shokh street, 32, Uzbekistan \\ ${ }^{4}$ Tashkent Institute of Irrigation and Agricultural Mechanization Engineers (TIIAME), State \\ Cadasters Department, 39 Kari Niyazov Street, Uzbekistan
}

\begin{abstract}
The features of the organization of production units - agroclusters, which are one of the components of land management projects which aimed at organizing the rational and efficient use of available land resources are described in this article. The term "cluster" is a French word that means "bundle", "collection" in Uzbek. It can be taken as "the geographical proximity of enterprises and institutions cooperating with each other in a particular field". The development of value-added production in the agricultural sector and the development of this market requires ensuring product quality standards, full use of scientific and scientific achievements in the processing process, development of existing research institutes and using the potential of geographical location. In our view, the solution of this problem can be found in the agricultural production system through the organization of cluster production, which is used by developed countries in America, Europe and Asia.
\end{abstract}

Keywords: agriculture, land management, project, agro-cluster, labor resources, land fund, land plot, productivity.

\section{Introduction}

In the conditions of formation of a competitive innovative economy in the Republic of Uzbekistan, including in the agricultural sector, ensuring the country's independence and food security, improving the living standards and quality of the rural population, poverty eradication, rational and efficient use of natural resources and environmental protection for future generations are the top priorities of the state.

It is known that the agricultural sector of the country has a great potential for the production and export of fruit and vegetables. The analysis shows that in the years when fruit and vegetables grown in the country exceed domestic demand, the average price of the

* Corresponding author: abduganimuratov59@gmail.com 
product in the domestic market decreases, and farmers who grow crops suffer. In addition, a low market prices hinder the release of products into the market, resulting in the loss of most products before they reach the consumer. Among many other factors, a poor sales system is a major obstacle to falling average market prices or increasing losses. This, in turn, has worsened the economic situation of agricultural enterprises, leading to problems in providing the country's population with quality food products. It is well known that ensuring sustainable agricultural production requires not only a short-term approach to increasing production, but also a long-term approach to processing and balanced distribution of products throughout the supply chain.

\section{Materials and methods}

According to the sources [1], the basis of the "cluster" theory is Alfed Marshall's "Principles of Economics", written in the late nineteenth century. According to its scientific findings, the territorial harmonization of specialized entities is based on the following:

- availability of qualified labour resources;

- growth of supplier and ancillary industries;

- existence of specialization in different links of production processes of different enterprises.

In recent years, the cluster theory has become popular by setting different goals and applying them in practice. Some views prioritize clustering quality over geographic location, others prioritize networking, and still others prioritize innovation.

According to British theorists (J. Dunning, K. Briman, J. Humphrey), a cluster is an institutional theory that defines the basis of the economy as a system of interacting institutions. In this case, the cluster itself is considered a modern institution. Scandinavian scientists (B. Lundwal, B. Johnson, B. Asheim, A. Isaacson) say that the evolution of the cluster has gone through a number of stages.

The theory of clusters has been studied by Russian scientists [2], and projects have been developed for its implementation [3, 4].

In our view, the development of cluster theory can be described in two ways (Figure 1).

The concept of cluster

The first concept is that a cluster-based raw material processing and processing enterprise must be linked to a specific type of commodity market. This relationship is vertical (chain of purchases and sales) and horizontal (services, technologies, institutions and other relationships).

The second concept is that clusters are a group of geographically close interconnected enterprises that, as a result of the stabilization of economic and social relations between them, develop competitiveness, create more value added and create opportunities for sale in the market.

Fig. 1. Description of the cluster concept 


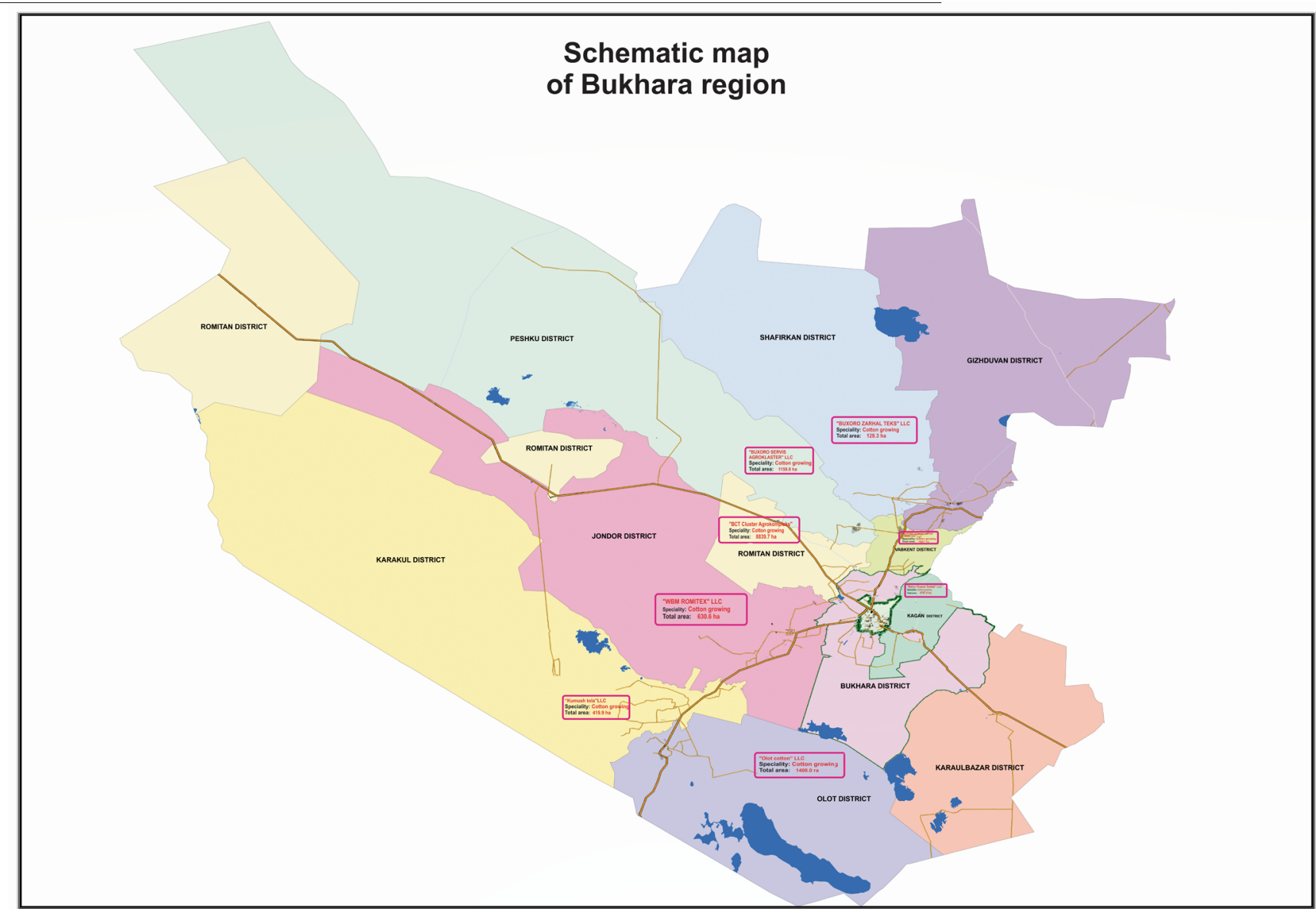

Fig. 2. Scheme of location of cotton agro-clusters in the region 
The descriptions of the concept of clusters emphasize that the interaction between enterprises and organizations ensures the economic efficiency of clusters. By further refining and expanding these theoretical definitions, the "agrocluster-village improving the competitiveness of agricultural products in the domestic and foreign markets, the formation and development of infrastructure in rural areas, increasing employment and incomes of the rural population and improving the environment through the integration of production, processing and sales of agricultural products into a single chain and the use of high technology innovations is a business entity" engaged in focused activities.

In the Bukhara region, agro-clusters are mainly organized in the following areas: cotton, livestock, horticulture, vegetable growing.

It has the highest number of cotton clusters and is organized regionally in Jondor, Romiton, Vobkent, Alat, Shafirkan, Kagan, Karakul districts of the region (Figure 2).

It is known that the cotton complex is an important element of the socio-economic sphere of the region. At the same time, the potential of this industry is not fully used. One of the problems hindering the development of this sector of the agro-industrial complex is the lack of storage and processing facilities, the lack of modern technologies and the availability of agricultural machinery, and others.

Fruit and vegetable agro-clusters are the second largest agro-clusters in the region. Territorially, they are located in Bukhara, Karavulbozor and Gijduvan districts of the region.

The advantage of agro-clusters in this direction is that they are located on the basis of existing orchards and vineyards and close to large settlements. It is known that the area of agro-clusters in this area is not very large. The main reasons for this are that the processes of planting, processing and harvesting are still largely manual, the capacity of storage and processing enterprises is low, the crop is not guaranteed by the state, and so on [5].

The agro-cluster is the only one in the region located in Karakul district of the region.

As part of the regional land fund (Table 1), the agro-cluster is organized on an area of 361.2 hectares, with hayfields and pastures covering 2541.3 thousand hectares. Factors contributing to this situation include a low yields of forage crops in natural pastures (1.5$2.0 \mathrm{~s} / \mathrm{ha}$ ) for year-round grazing of livestock, and degradation of pastures.

Table. 1. Regional land fund

\begin{tabular}{|c|c|c|c|c|c|c|c|c|c|c|c|}
\hline \multirow[b]{2}{*}{ № } & \multirow[b]{2}{*}{$\begin{array}{l}\text { Land type } \\
\text { name }\end{array}$} & \multicolumn{2}{|c|}{ Land area } & \multicolumn{2}{|c|}{$\begin{array}{l}\text { Cultivated } \\
\text { lands }\end{array}$} & \multicolumn{2}{|c|}{$\begin{array}{c}\text { Lands } \\
\text { occupied by } \\
\text { trees }\end{array}$} & \multicolumn{2}{|c|}{$\begin{array}{l}\text { Unused } \\
\text { lands }\end{array}$} & \multicolumn{2}{|c|}{ Pastures } \\
\hline & & 吾 & 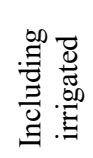 & 䒿 & 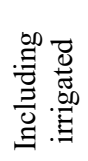 & 吾 & 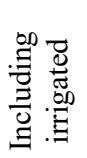 & 퓽 & 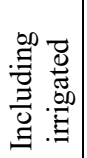 & 䒿 & 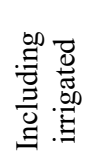 \\
\hline 1 & $\begin{array}{c}\text { Types of } \\
\text { agricultural } \\
\text { land }\end{array}$ & 2769.0 & 227.6 & 201.2 & 201.2 & 19.5 & 19.5 & 6.9 & 6.9 & 2541.3 & - \\
\hline
\end{tabular}

Due to the lack of water resources in the 676,106,000 hectares of land in Alat, Gijduvan, Peshku and Jondor districts of the region, it is not possible to establish yearround cultural pastures that require large capital expenditures. However, there is an opportunity to organize agro-clusters in 4 livestock areas, specializing in karakul due to the organization of rotational grazing. 


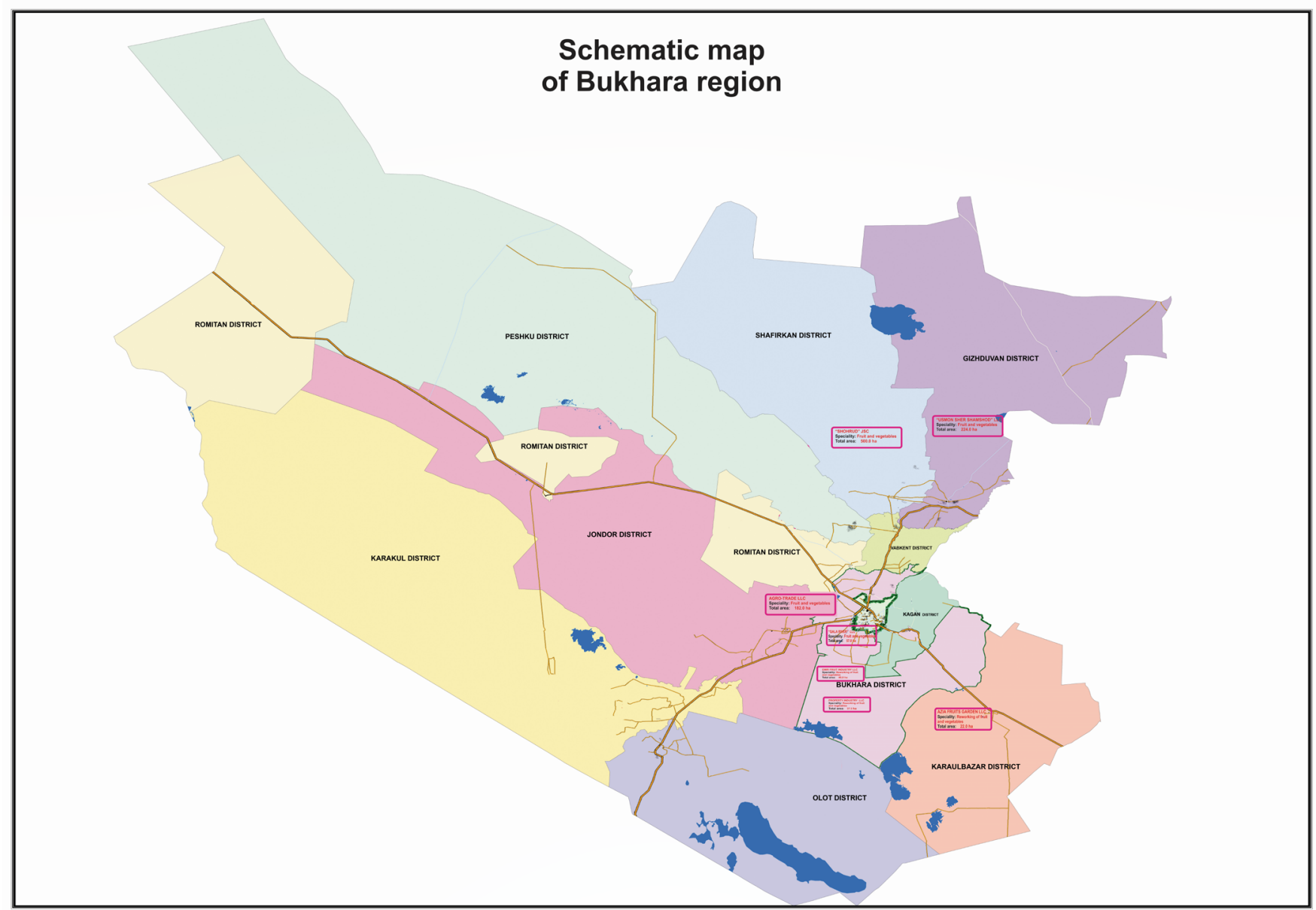

Fig. 3. Scheme of location of agro-clusters in the field of fruit and vegetable growing in the region 


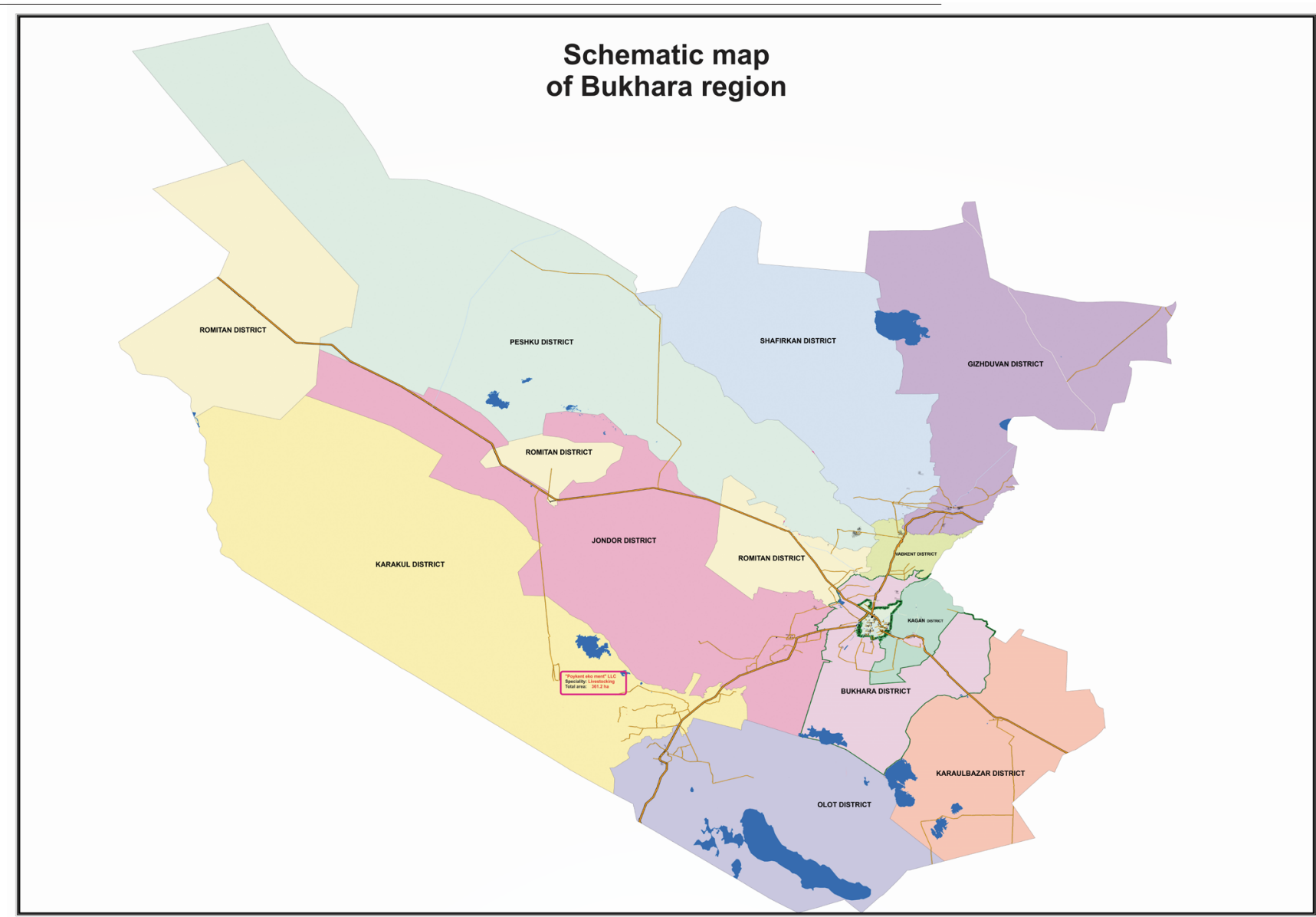

Fig. 4. Scheme of the location of agro-clusters in the field of livestock in the region 


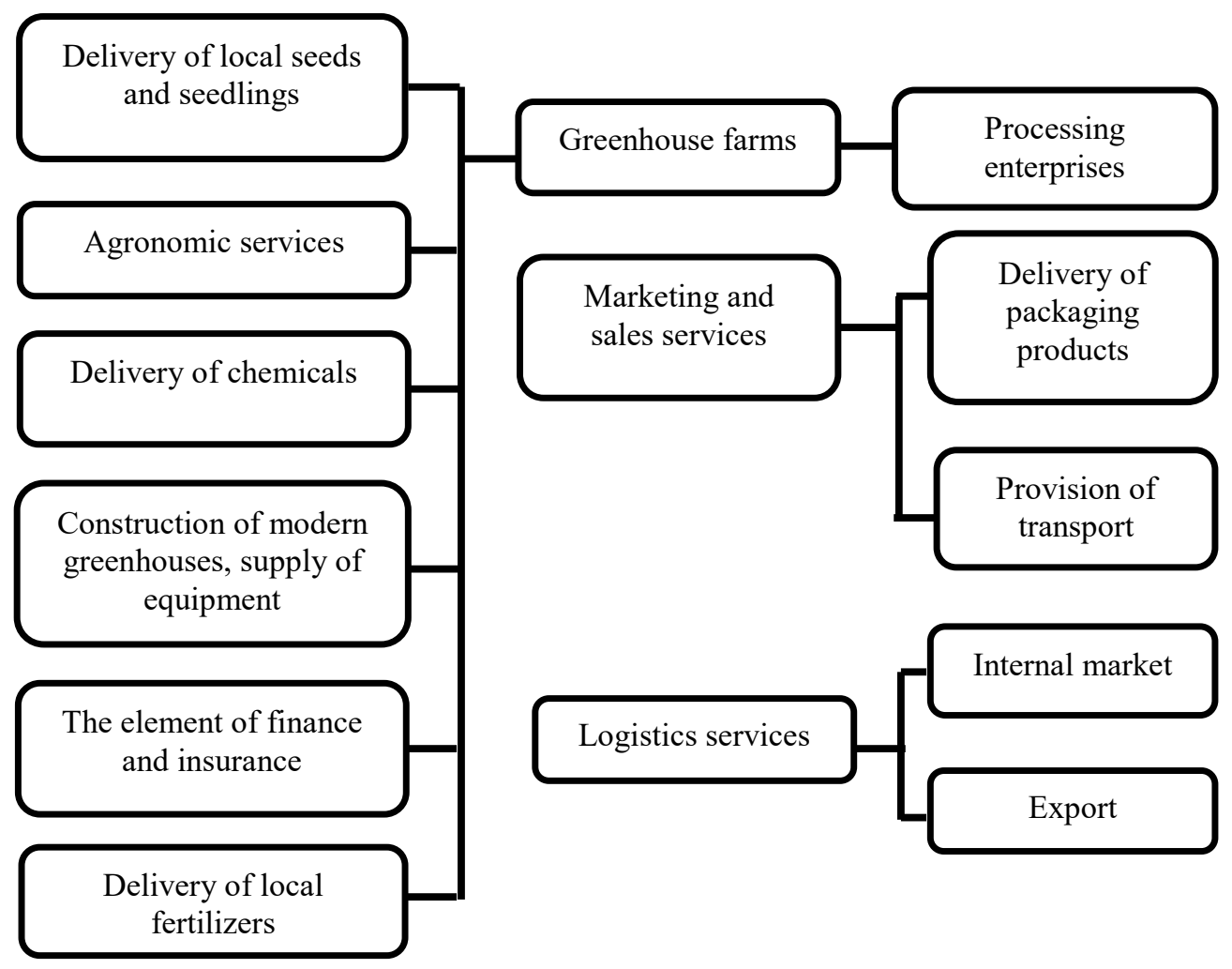

Fig.5. Developed scheme of the agro-clusters in Bukhara region

\section{Results}

It is known that the application of cluster theory has its own characteristics in different countries and industries, but it also has a number of features that are common to all countries. In our opinion, they are as follows:

- enterprises (firms) have the opportunity to increase labour productivity and production efficiency due to their direct connection to suppliers, qualified specialists, information supply, service and training centres. In enterprises located in clustered areas, the increase in labour productivity by 1.5 times and salary by up to $30 \%$ has been confirmed in practice.

- financial opportunities will be created to encourage scientists and specialists who have achieved high results by conducting effective research activities.

One of the important features of the formation of clusters in our country, in contrast to other countries, is the role of the state.

The development of the agricultural sector on a cluster basis requires the organization of ancillary suppliers, service providers and processors [6]. Therefore, the following scheme has been developed in Bukhara region to create an agro-cluster to increase agricultural production, improve its composition, introduce innovative and resource-saving technologies in the industry (Figure 5).

An important aspect of the organization of the agro-cluster is to strengthen the trust of its members through the implementation of joint projects that combine the processes of joint cultivation, processing - sale - research, [7, 8, 9]. With this in mind, the following scheme is proposed for the creation of a chain of value added of food products in agroclusters organized for the cultivation of livestock and agricultural products (Figure 6). 


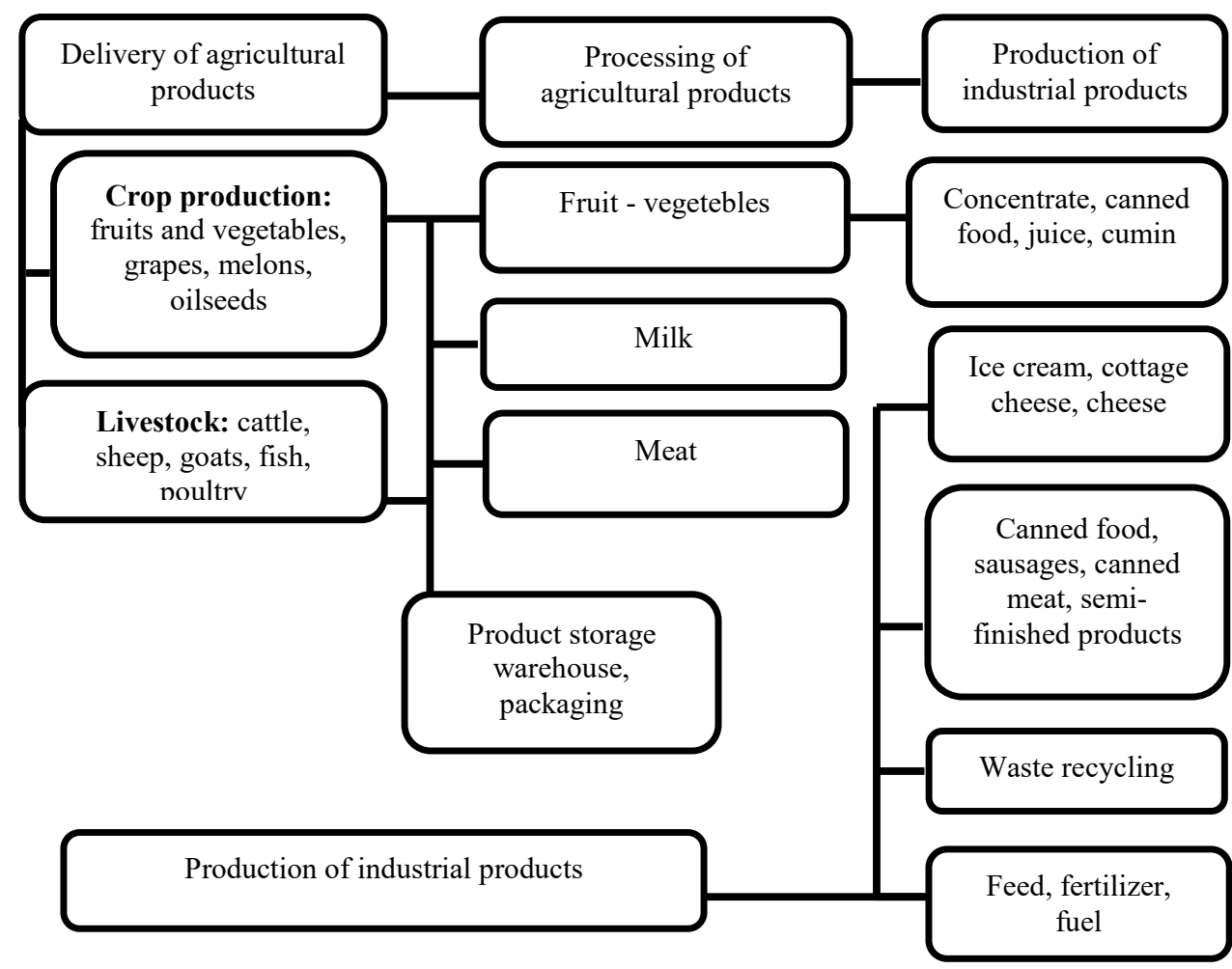

Fig. 6. Proposed scheme for the creation of a chain of value added of food products in agro-clusters

In our opinion, the implementation of the recommended scheme for creating a value chain of food products in agricultural clusters (Fig. 6) will serve as a mechanism for strengthening the confidence of its participants through the implementation of joint projects that combine the processes of joint cultivation of agricultural and other products, their processing-sale-research.

The authors would like to thank Sadulla Avezbaev for his suggestions in this paper.

\section{References}

1. M. A. Rakhmatov, V. Z. Zaripov. Cluster integration, innovation and economic growth. Tashkent, Zamin Nashr, 165 p (2018)

2. I. V. Andronova, Yu. P. Bachinina, Cluster approach in the ensuring of the competitiveness of the region. Monograph - Tyumen: Tyumen state oil and gas University, $120 \mathrm{p}$ (2010)

3. S. Avezbaev, S.N.Volkov, Automated design systems in land management. Textbook. Toshkent, 168 b (2010)

4. S. N. Volkov, Automated design systems in land management. Textbook. Moscow, 667 p (2018)

5. A. S. Chertovitsky, A. K. Bazarov, Land use Economics. Textbook. Tashkent, TIIM, $220 \mathrm{p}(2009)$

6. U. P. Umurzakov, Improving the efficiency of using the resource potential of the agricultural sector of the economy of Uzbekistan. Monograph. Tashkent, "Fan", $211 \mathrm{p}$ (2005) 
7. T. V. Papaskiri, Geoinformation systems and computer-aided design technologies in land management. Educational and methodological guide (4th edition, revised and supplemented) - Moscow: publishing house "New printing technologies", 249 p (2013)

8. T. V. Papaskiri, Automation of land management design and land management (efficiency and organization). Land management, cadastre and land monitoring, Moscow: Panorama publishing house, Athena publishing House, 5, Pp. 12-22 (2014)

9. F. R. Hamidov, The role of land management in organization of rational use and protection. European Sciences review Scientific journal № 11-12 (NovemberDecember), (2017)

10. Land Records and the Role of Government. — London: Land and Property Economics, p.10 (2001)

11. Google Maps. - Access mode: https://www.google.com/maps 